\title{
Evaluating the validity of using unverified indices of body condition
}

\author{
Jason L. Schamber, Daniel Esler and Paul L. Flint \\ J. L. Schamber (correspondence) and P. L. Flint, Alaska Science Center, U.S. Geological Survey, 4210 Univ. Drive, Anchorage, Alaska 99508, \\ USA. E-mail: jschamber@usgs.gov. - D. Esler, Centre for Wildlife Ecology, Simon Fraser Univ., 5421 Robertson Road, Delta, British Columbia \\ V4K 3N2, Canada.
}

\begin{abstract}
Condition indices are commonly used in an attempt to link body condition of birds to ecological variables of interest, including demographic attributes such as survival and reproduction. Most indices are based on body mass adjusted for structural body size, calculated as simple ratios or residuals from regressions. However, condition indices are often applied without confirming their predictive value (i.e., without being validated against measured values of fat and protein), which we term 'unverified' use. We evaluated the ability of a number of unverified indices frequently found in the literature to predict absolute and proportional levels of fat and protein across five species of waterfowl. Among indices we considered, those accounting for body size never predicted absolute protein more precisely than body mass, however, some indices improved predictability of fat, although the form of the best index varied by species. Further, the gain in precision by using a condition index to predict either absolute or percent fat was minimal (rise in $r^{2} \leq 0.13$ ), and in many cases model fit was actually reduced. Our data agrees with previous assertions that the assumption that indices provide more precise indicators of body condition than body mass alone is often invalid. We strongly discourage the use of unverified indices, because subjectively selecting indices likely does little to improve precision and might in fact decrease predictability relative to using body mass alone.
\end{abstract}

Use of the term body condition is pervasive in ecological literature, yet the term is often undefined. Most authors explicitly or implicitly consider body condition to be a measure of nutrient reserves, where reserves are the quantity of utilizable tissues exceeding those required to meet daily nutritional demands (Owen and Cook 1977, Green 2001, Schulte-Hostedde et al. 2005). As such, body condition has been linked to a wide variety of individual attributes such as survival, productivity, habitat use, and behavior across a broad range of taxa, including birds. Further, relationships between demographic attributes and body condition have broader implications for population dynamics, therefore, researchers interested in quantifying these relationships look for reliable methods of estimating body condition.

In simple terms, animal bodies consist of four basic components: protein, lipid, mineral, and water. Except for minimal structural functions, lipid is not essential for fundamental existence, thus, almost all lipid can be catabolized and is therefore considered 'reserve'. Conversely, only some proportion of total body protein could be deemed 'reserve', because a substantial fraction of protein is structural and consequently, is required for an animal's basic existence. Additionally, although both protein and lipid can be used for energy, the net energetic value of lipid is considerably higher than that of protein (Robbins 1993). Thus, on a per unit mass basis, lipid is far more valuable in terms of an energetic relationship with fitness; conse- quently, variation in condition is most often attributed to variation in lipid.

Unfortunately, direct measurement of total body fat and protein requires destructive sampling. Therefore, direct measures of body condition can only be used in retrospective analyses, wherein the condition of an individual can be related to its status at or before the time of collection. However, many ecological questions can only be answered by relating an individual's body condition to future performance (e.g., survival or reproductive success). Thus, many researchers have attempted to develop indices to body condition to evaluate relationships between these indices and ecological attributes of interest.

The simplest and most commonly applied index is that of field measured body mass, which represents the sum of energy stores and structural mass. However, body mass could be considered a naïve index because it does not estimate condition independent of structural size (Johnson et al. 1985, Ringelman and Szymczak 1985). Inherently, larger-bodied individuals tend to have greater structural mass than smaller conspecifics (Heusner 1982), therefore, unadjusted body mass theoretically could mask variation in condition among individuals. Arguably, scaling body mass by individual morphological characters or a composite measure (e.g., a principal components score from a suite of morphometric measures) could remove potential sizerelated variation and thereby increase the precision of an estimate of condition. Thus, most condition indices are 
used to functionally separate mass of nutrient reserves from mass of structural size by scaling body mass with measures of body size. This is most often done by using one of two methods: 1. calculating simple ratios of body mass and linear body size measures (ratios; e.g., Owen and Cook 1977, Iverson and Vohs 1982, Dufour and Weatherhead 1991), or 2. calculating the residuals from a regression of body mass against size indicators (residuals; e.g., Ormerod and Tyler 1990, Brown 1996). Although use of these sizeadjusted indices is common, a surprisingly small number have been verified (i.e., tested against measured values of fat and protein) to outperform the use of unadjusted body mass. Unfortunately, this dearth of validated indices has led to the widespread use of unverified condition indices, wherein researchers have applied indices developed for other species or have arbitrarily selected indices and provided no justification for their use. That is, indices were created from an available data set of body size metrics and were assumed to provide a more precise index of body condition than use of body mass alone. This approach assumes that any correction for body size, whether verified or not, represents condition better than uncorrected body mass. However, various published predictive equations, which are based on regressions of size-adjusted body mass on actual values of fat and protein obtained from dead animals (e.g., Conway et al. 1994, van der Meer and Piersma 1994), varied interspecifically (Sparling et al. 1992), suggesting that indices are inappropriate for species other than those for which the index was developed (Chappell and Titman 1983). Moreover, index applicability within species may vary by sex (Sparling et al. 1992) or age (Ringelman 1988, Sparling et al. 1992), and is likely complicated by variation in geographic area and/or season (Miller 1989, Castro and Myers 1990, Sparling et al. 1992). Thus, limitations on the use of validated indices suggest that the use of unverified indices is questionable and several authors have cautioned against their use (e.g., Ormerod and Tyler 1990, Sparling et al. 1992, van der Meer and Piersma 1994).

In this paper, we use data from several waterfowl species to evaluate the use of various, commonly applied indices as indicators of lipid and protein. For a number of reasons, waterfowl are useful taxa to use for this exercise. First, numerous studies have examined variation in body condition throughout the annual cycle, resulting in accessible data sets where structural measures and total body protein and lipid have already been determined. Secondly, waterfowl tend to show large fluctuations in protein and lipid throughout the annual cycle, allowing us to explore the fit of condition indices across a broad range of true body conditions. Finally, because body condition could be a determinant of demographic characteristics in waterfowl, investigators have examined relationships between condition indices and vital rates such as survival (Hepp et al. 1986, Conroy et al. 1989, Sheeley and Smith 1989, Bergan and Smith 1993, Dugger et al. 1994), and reproduction (Arnold et al. 1995, Yerkes 1998, Blums et al. 2002, Bustnes et al. 2002, Perfito et al. 2002).

We examined the predictive value of condition indices across five species of Anatidae: northern pintail Anas acuta (hereafter pintail), lesser scaup Aythya affinis (hereafter scaup), American wigeon Anas americana (hereafter wigeon), Harlequin duck Histrionicus histrionicus (hereafter harlequin), and Barrow's goldeneye Bucephala islandica (hereafter goldeneye) collected at various stages of the annual cycle. Our objective was to explore a range of indices to body condition that have been commonly used on live birds, but often applied without verification. We examined the predictive abilities of these indices, which included body mass, ratios, and residuals, relative to measured levels of protein and lipid. We also considered that investigators variably define body condition in terms of either absolute quantities or relative amounts of protein or lipid depending on the ecological question of interest. For example, investigators likely define condition in absolute terms, the quantity of reserves regardless of body size, when examining the influence of reserves on egg production (Alisauskas and Ankney 1992). In contrast, investigators examining survival (Hohman 1993) likely define condition in relative terms, where the quantity of reserves is corrected for body mass to a proportional scale. Thus, we tested the predictive abilities of these indices relative to two theoretical definitions of condition: 1. absolute reserves or the actual amount of fat and protein; and 2. proportional reserves, or the measured amount of fat and protein scaled for body mass (e.g., fat $\times$ body mass $^{-1}$ ). Finally, we developed predictive equations to provide a standard by which we compared the performance of the unverified indices we tested. Predictive equations are currently the most precise method for estimating individual body condition because estimates of model parameter coefficients for mass and/or size-metrics are based on measured values of fat and protein. Conversely, unverified indices are not validated against known tissue values, and therefore, parameter coefficients are not directly estimated (i.e., they are assumed to be 1.0). Thus, the fit of the predictive equations we developed set the upper limit for the variation that potentially can be explained by the unverified indices that we examined. In other words, a particular unverified index can either equal the precision with which a corresponding equation predicts condition, or predict condition less precisely. We note that the intent of this paper was not to develop usable indices of body condition (such indices require cross-validation; Sparling et al. 1992) for our study species, but to examine the appropriateness of applying unverified indices in a general way.

\section{Methods}

We used data from birds collected during previous field studies with separate objectives. Samples included 179 female pintail, 57 female scaup, and 51 female wigeon collected during various stages of the breeding cycle on the Yukon Flats and Yukon-Kuskokwim Delta, Alaska. Additionally, we used data from 37 adult goldeneye (14 females and 23 males) wintering in Prince William Sound, Alaska, and 21 adult female harlequins molting at Kodiak Island, Alaska. For breeding birds we field measured and logtransformed body mass, diagonal tarsus (hereafter tarsus; Miller et al. 1988), culmen length (hereafter culmen), wingchord (Dzubin and Cooch 1992), and body length (Eichholz and Sedinger 2006). For harlequin and goldeneye, we field measured and log-transformed body mass (we used thawed carcass mass in the lab as a field body mass 
proxy for goldeneye because field body mass was unavailable), tarsus, and culmen.

For each species, we used the available (four or two) body size metrics to construct the first principal component (PC1) based on the correlation matrix from a principal components analysis (SAS Institute 2003). PC1 loadings for pintail, scaup, and wigeon were positively correlated with all morphological measures (ranges of loadings 0.37-0.55, $0.27-0.62$, and $0.38-0.56$, respectively), accounting for $43 \%, 40 \%$, and $45 \%$ of total variance, respectively. PC1 for harlequin was positively correlated with measures of culmen and tarsus and explained $62 \%$ of total variance. In each analysis of male and female goldeneye, PC1 was positively correlated with tarsus, but described a negative correlation with culmen. PC1 explained $80 \%$ and $86 \%$ of total variance for males and females, respectively.

We estimated total body fat (fat) and ash-free lean (afl; i.e., approximated protein), using standard proximate body composition analyses. In brief, carcasses were dried, homogenized, and lipid was extracted from a subsample using petroleum ether in a soxhlet apparatus (Dobush et al. 1985). We determined afl through combustion of lipid-free material in a muffle furnace for $24 \mathrm{~h}$ to determine proportions of protein and mineral (Ankney and Afton 1988). Total fat and protein were estimated by extrapolating the composition of the subsample to the dry mass of the entire carcass.

We examined sex differences in thaw mass of goldeneye by using a small-sample version of Akaike's information criterion ( $\mathrm{AIC}_{\mathrm{c}}$; Burnham and Anderson 2002) to contrast a model with a sex term against an equal means model. The most parsimonious model of the candidate set, that is, the model that best fits the data without over-parameterization, will have the lowest $\mathrm{AIC}_{\mathrm{c}}$ and a high $\mathrm{AIC}_{\mathrm{c}}$ weight $\left(\mathrm{w}_{\mathrm{i}}\right)$ on a 0 to 1 scale.

\section{Predictive equations}

We developed predictive models of absolute fat and protein for all species using ordinary least squares (OLS) regressions (PROC GLM, SAS Institute 2003); including log-transformed body mass and structural measurements as independent variables. To satisfy assumptions of linearity and homoscedasticity using allometric variables in our analyses, we also log-transformed the estimated values of fat and protein.

For pintail, scaup, and wigeon we considered models that included only body mass, body mass + a single morphometric (either tarsus, culmen, wing-chord, or body length), and the most complex additive combination of morphometrics (i.e., body mass + tarsus + culmen + wingchord + body length). We also included a model containing body mass and PC1. For goldeneye and harlequin, the model sets consisted of body mass alone and body mass with all additive combinations of tarsus and culmen, as well as a model for body mass and PC1. We compared predictive abilities of these models using $r^{2}$ model fit and $\Delta r^{2}$ (the absolute change in $r^{2}$ value relative to the $r^{2}$ of a model including only body mass).

\section{Ratio and residual indices}

We evaluated the ability of oft-used indices to explain variation in both absolute (measured tissue value) and percent (measured tissue value $\times$ body mass $^{-1}$ ) fat and protein, relative to that of body mass alone, by regressing several common forms of log-transformed indices against log-transformed values of fat and protein (absolute or percent). For pintail, scaup, and wigeon we scaled (divided) body mass by tarsus, culmen, wing-chord, and body length in turn. For harlequin and goldeneye, we scaled (divided) body mass by tarsus and culmen and we conducted regressions separately for each goldeneye sex. We also examined the predictive ability of OLS residuals of body mass regressed against morphometrics or PC1 of each species. These included OLS residuals of body mass regressed against a combination of structural measures found in the most complex predictive equations for each species.

\section{Results}

\section{Predictive equations}

We compared seven models separately for both protein and fat of female pintail, scaup, and wigeon. We considered only five models each for protein and fat of goldeneye and harlequin, because we measured only two morphological characters for each of these species. Additionally, we considered models for both sexes separately in goldeneye because a model with a sex term was a much more parsimonious model for explaining variation in thaw mass $\left(w_{i}>0.99\right)$, than a null model.

Inherently, models for all species that included an added parameter of body size metrics improved precision of fat and protein prediction relative to body mass alone, although in a few cases predictive ability was essentially equivalent to a body mass model. Accordingly, the most complex models best fit the data compared to all other models and represented maximal gains in precision relative to body mass. With the exception of fat of wigeon and goldeneye, inclusion of morphometrics in complex models improved $r^{2}$ above that explained by body mass alone by $\leq 0.09$ for both fat and protein (Table 1).

\section{Ratio and residual indices}

\section{Absolute values}

Body mass was the most precise predictor of protein among all species (Table 2). Thus, in every case an index either predicted protein with equal precision as body mass or precision was reduced relative to body mass (Table 2 ). In contrast, the ability of indices to predict fat relative to body mass was variable by model structure and across species, although residual indices generally outperformed ratio indices. For example, the ratio of body mass to tarsus, which was a shared index among species, best predicted fat of wigeon only, but was among the poorest performing indices for all other species (Table 2). However, the residuals of body mass fit to tarsus, also a shared index, most precisely predicted fat of scaup and female goldeneye, but fit less well for all other species (Table 2). Across 
Table 1. Model sets for fat and protein of all species that include structure of the simplest model (body mass only), body mass $+($ single) morphometric, most complex model (all parameters), as well as body mass and PC1. Values shown in bold type denote highest $\Delta \mathrm{r}^{2}$ among indices considered within a species and tissue type.

\begin{tabular}{|c|c|c|c|c|c|c|}
\hline Species & FAT $^{\mathrm{b}}$ models & $r^{2}$ & $\left(\Delta r^{2}\right)^{c}$ & PROTEIN ${ }^{b}$ models & $r^{2}$ & $\left(\Delta r^{2}\right)^{c}$ \\
\hline \multirow[t]{7}{*}{ Northern pintail } & Mass & 0.52 & 0.00 & Mass & 0.68 & 0.00 \\
\hline & Mass + Tarsus & 0.55 & 0.03 & Mass + Tarsus & 0.72 & 0.04 \\
\hline & Mass + Culmen & 0.55 & 0.03 & Mass + Culmen & 0.71 & 0.03 \\
\hline & Mass + Wing & 0.54 & 0.02 & Mass + Wing & 0.69 & 0.01 \\
\hline & Mass + Body & 0.54 & 0.02 & Mass + Body & 0.70 & 0.02 \\
\hline & Mass + Tarsus + Culmen + Wing + Body & 0.59 & 0.07 & Mass + Tarsus + Culmen +Wing + Body & 0.74 & 0.06 \\
\hline & Mass + PC1 & 0.58 & 0.06 & Mass + PC1 & 0.73 & 0.05 \\
\hline \multirow[t]{7}{*}{ Lesser scaup } & Mass & 0.27 & 0.00 & Mass & 0.58 & 0.00 \\
\hline & Mass + Tarsus & 0.29 & 0.02 & Mass + Tarsus & 0.59 & 0.01 \\
\hline & Mass + Culmen & 0.30 & 0.03 & Mass + Culmen & 0.58 & 0.00 \\
\hline & Mass + Wing & 0.27 & 0.00 & Mass + Wing & 0.63 & 0.05 \\
\hline & Mass + Body & 0.28 & 0.01 & Mass + Body & 0.60 & 0.02 \\
\hline & Mass + Tarsus + Culmen + Wing + Body & 0.33 & 0.06 & Mass + Tarsus + Culmen + Wing + Body & 0.64 & 0.06 \\
\hline & Mass + PC1 & 0.27 & 0.00 & Mass + PC1 & 0.62 & 0.04 \\
\hline \multirow[t]{7}{*}{ American wigeon } & Mass & 0.27 & 0.00 & Mass & 0.60 & 0.00 \\
\hline & Mass + Tarsus & 0.39 & 0.12 & Mass + Tarsus & 0.63 & 0.03 \\
\hline & Mass +Culmen & 0.27 & 0.00 & Mass +Culmen & 0.65 & 0.05 \\
\hline & Mass + Wing & 0.32 & 0.05 & Mass + Wing & 0.61 & 0.01 \\
\hline & Mass+Body & 0.38 & 0.11 & Mass + Body & 0.65 & 0.05 \\
\hline & Mass + Tarsus +Culmen +Wing + Body & 0.45 & 0.18 & Mass + Tarsus + Culmen + Wing + Body & 0.69 & 0.09 \\
\hline & Mass + PC1 & 0.40 & 0.13 & Mass + PC1 & 0.68 & 0.08 \\
\hline \multirow[t]{5}{*}{ Harlequin duck } & Mass & 0.83 & 0.00 & Mass & 0.74 & 0.00 \\
\hline & Mass + Tarsus & 0.83 & 0.00 & Mass + Tarsus & 0.76 & 0.02 \\
\hline & Mass + Culmen & 0.84 & 0.01 & Mass + Culmen & 0.74 & 0.00 \\
\hline & Mass + Tarsus + Culmen & 0.84 & 0.01 & Mass + Tarsus + Culmen & 0.77 & 0.03 \\
\hline & Mass + PC1 & 0.83 & 0.00 & Mass + PC1 & 0.75 & 0.01 \\
\hline \multicolumn{7}{|l|}{ Barrow's goldeneye } \\
\hline \multirow{5}{*}{ Female } & Mass & 0.22 & 0.00 & Mass & 0.77 & 0.00 \\
\hline & Mass + Tarsus & 0.42 & 0.20 & Mass + Tarsus & 0.78 & 0.01 \\
\hline & Mass + Culmen & 0.25 & 0.03 & Mass +Culmen & 0.78 & 0.01 \\
\hline & Mass + Tarsus + Culmen & 0.45 & 0.23 & Mass + Tarsus + Culmen & 0.78 & 0.01 \\
\hline & Mass + PC1 & 0.34 & 0.12 & Mass + PC1 & 0.78 & 0.01 \\
\hline \multirow[t]{5}{*}{ Male } & Mass & 0.25 & 0.00 & Mass & 0.71 & 0.00 \\
\hline & Mass + Tarsus & 0.68 & 0.43 & Mass + Tarsus & 0.72 & 0.01 \\
\hline & Mass + Culmen & 0.36 & 0.11 & Mass + Culmen & 0.71 & 0.00 \\
\hline & Mass + Tarsus + Culmen & 0.69 & 0.44 & Mass + Tarsus + Culmen & 0.73 & 0.02 \\
\hline & Mass + PC1 & 0.56 & 0.31 & Mass + PC1 & 0.71 & 0.01 \\
\hline
\end{tabular}

${ }^{\mathrm{a}} \mathrm{FAT}=$ total lipid, PROTEIN $=$ total protein.

${ }^{\mathrm{b}}$ Abbreviation for model parameters: Mass = body mass, Tarsus = diagonal tarsus, Culmen =culmen length, Wing = wing chord, Body $=$ body length, PC1 = first principal component.

${ }^{\mathrm{c}} \Delta \mathrm{r}^{2}=$ the change in percent variation explained when morphometrics are included in a model with body mass relative to a model with body mass only.

species, increases to model fit $\left(\mathrm{r}^{2}\right)$ of fat indices relative to that of body mass alone were $\leq 0.12$. Maximum reductions in model fit relative to body mass were $0.03-0.38$ (Table 2 ).

\section{Percent values}

In general, the ability of indices to predict percent protein was poor; maximums of model fit ranged from $<0.01$ to 0.22 (Table 3 ). Predictive ability varied by model structure and species, however, in most cases indices predicted percent protein as well as or more precisely than body mass alone (Table 3).

In all but two cases, indices predicted percent fat with less precision than they predicted absolute fat. However, the pattern of variation in the ability of indices to predict percent fat was generally similar to that found for predicting absolute fat (Table 3). That is, the ability of indices to predict percent fat relative to body mass was variable by model structure and across species. Improvements to model fit $\left(\mathrm{r}^{2}\right)$ of indices relative to that of body mass alone across species were $\leq 0.13$. Maximum reductions in model fit relative to body mass were $0.03-0.36$ (Table 3 ).

\section{Discussion}

The results from our analyses indicated that the predictive ability of indices varied among species and often differed between tissues (fat and protein) within a species, as well as between sexes in goldeneye. Hence, our analyses strongly indicated that no single index formulation is universally 
Table 2. Relative measures of model fit $\left(\mathrm{r}^{2}\right)$ from regressions of FAT (total lipid) and PROT (total protein) against indices (body mass, ratio or residual) for five waterfowl species. Ratio indices include body mass divided by structural measures. Residual indices are based on the fit of a model for fat or protein by the residuals of a model of body mass as a function of the various combinations of structural measures. Values shown in bold type denote highest $r^{2}$ among indices considered within a species and tissue type.

\begin{tabular}{|c|c|c|c|c|c|c|c|c|c|c|c|c|}
\hline \multirow[t]{4}{*}{ Models $^{\mathrm{a}}$} & \multicolumn{12}{|c|}{ Species } \\
\hline & \multicolumn{2}{|c|}{ Northern pintail } & \multicolumn{2}{|c|}{ Lesser scaup } & \multicolumn{2}{|c|}{ American wigeon } & \multicolumn{2}{|c|}{ Harlequin duck } & \multicolumn{4}{|c|}{ Barrow's goldeneye } \\
\hline & \multirow[b]{2}{*}{ FAT } & \multirow[b]{2}{*}{ PROT } & \multirow[b]{2}{*}{ FAT } & \multirow[b]{2}{*}{ PROT } & \multirow[b]{2}{*}{ FAT } & \multirow[b]{2}{*}{ PROT } & \multirow[b]{2}{*}{ FAT } & \multirow[b]{2}{*}{ PROT } & \multicolumn{2}{|c|}{ Female } & \multicolumn{2}{|c|}{ Male } \\
\hline & & & & & & & & & FAT & PROT & FAT & PROT \\
\hline Mass & 0.52 & 0.68 & 0.27 & 0.58 & 0.27 & 0.60 & 0.83 & 0.74 & 0.22 & 0.77 & 0.25 & 0.71 \\
\hline \multicolumn{13}{|l|}{ Ratios: } \\
\hline Mass/Tarsus & 0.46 & 0.27 & 0.28 & 0.40 & 0.39 & 0.30 & 0.52 & 0.61 & $<0.01$ & 0.26 & 0.07 & 0.14 \\
\hline Mass/Culmen & 0.47 & 0.30 & 0.28 & 0.43 & 0.18 & 0.23 & 0.69 & 0.57 & 0.04 & $<0.01$ & 0.33 & 0.30 \\
\hline Mass/Wing & 0.50 & 0.47 & 0.20 & 0.33 & 0.30 & 0.28 & & & & & & \\
\hline Mass/Body & 0.48 & 0.39 & 0.18 & 0.39 & 0.37 & 0.22 & & & & & & \\
\hline \multicolumn{13}{|l|}{ Residuals: } \\
\hline Tarsus & 0.55 & 0.58 & 0.29 & 0.49 & 0.28 & 0.56 & 0.55 & 0.63 & 0.31 & 0.75 & 0.15 & 0.67 \\
\hline Culmen & 0.55 & 0.60 & 0.28 & 0.58 & 0.27 & 0.60 & 0.80 & 0.73 & 0.25 & 0.65 & 0.24 & 0.71 \\
\hline Wing & 0.54 & 0.60 & 0.25 & 0.50 & 0.32 & 0.33 & & & & & & \\
\hline Body & 0.53 & 0.53 & 0.20 & 0.44 & 0.36 & 0.41 & & & & & & \\
\hline $\begin{array}{l}\text { Tarsus + Culmen + } \\
\text { Wing + Body }\end{array}$ & 0.57 & 0.46 & 0.23 & 0.38 & 0.31 & 0.31 & & & & & & \\
\hline $\mathrm{PC} 1{ }^{\circ}$ & 0.58 & 0.46 & 0.25 & 0.39 & 0.38 & 0.37 & 0.79 & 0.72 & 0.31 & 0.70 & 0.20 & 0.70 \\
\hline Tarsus +Culmen & & & & & & & 0.45 & 0.59 & 0.19 & 0.63 & 0.15 & 0.65 \\
\hline
\end{tabular}

${ }^{a}$ Abbreviation for model parameters: Mass=body mass, Tarsus=diagonal tarsus, Culmen=culmen length, Wing = wing chord, Body = body length, $\mathrm{PC} 1=$ first principal component.

applicable. Additionally, in all but two cases, indices predicted absolute fat and protein more precisely than percent tissue values. Thus, the predictive ability of indices is dependent upon whether an investigator considers body condition in absolute or proportional terms in light of their ecological attribute of interest. We repeated our analyses using data that were not log-transformed, which is a common though inappropriate practice when creating condition indices, and found that the results were very similar and corroborated our original conclusions.

Table 3. Relative measures of model fit $\left(r^{2}\right)$ from regressions of \%FAT (total lipid $\times$ body mass ${ }^{-1}$ ) and \%PROT (total protein $\times$ body mass $^{-1}$ ) against indices (body mass, ratio or residual) for five waterfowl species. Ratio indices include body mass divided by structural measures. Residual indices are based on the fit of a model for \%FAT or \%PROT by the residuals of a model of body mass as a function of the various combinations of structural measures. Values shown in bold type denote highest $r^{2}$ among indices considered within a species and tissue type.

\begin{tabular}{|c|c|c|c|c|c|c|c|c|c|c|c|c|}
\hline \multirow[t]{4}{*}{ Models $^{\mathrm{a}}$} & \multicolumn{12}{|c|}{ Species } \\
\hline & \multicolumn{2}{|c|}{ Northern pintail } & \multicolumn{2}{|c|}{ Lesser scaup } & \multicolumn{2}{|c|}{ American wigeon } & \multicolumn{2}{|c|}{ Harlequin duck } & \multicolumn{4}{|c|}{ Barrow's goldeneye } \\
\hline & \multirow[b]{2}{*}{$\%$ FAT } & \multirow[b]{2}{*}{$\%$ PROT } & \multirow[b]{2}{*}{$\%$ FAT } & \multirow[b]{2}{*}{ \%PROT } & \multirow[b]{2}{*}{$\%$ FAT } & \multirow[b]{2}{*}{ \%PROT } & \multirow[b]{2}{*}{$\%$ FAT } & \multirow[b]{2}{*}{$\%$ PROT } & \multicolumn{2}{|c|}{ Female } & \multicolumn{2}{|c|}{ Male } \\
\hline & & & & & & & & & $\%$ FAT & \%PROT & $\%$ FAT & \%PROT \\
\hline Mass & 0.46 & $<0.01$ & 0.19 & 0.08 & 0.18 & 0.11 & 0.78 & $<0.01$ & 0.16 & 0.12 & 0.19 & 0.01 \\
\hline \multicolumn{13}{|l|}{ Ratios: } \\
\hline Mass/Tarsus & 0.43 & 0.08 & 0.21 & 0.10 & 0.31 & 0.18 & 0.50 & 0.02 & 0.01 & 0.02 & 0.10 & 0.01 \\
\hline Mass/Culmen & 0.43 & 0.06 & 0.22 & 0.05 & 0.13 & 0.22 & 0.66 & $<0.01$ & 0.04 & $<0.01$ & 0.29 & $<0.01$ \\
\hline Mass/Wing & 0.45 & 0.02 & 0.14 & 0.16 & 0.23 & 0.15 & & & & & & \\
\hline Mass/Body & 0.44 & 0.04 & 0.12 & 0.12 & 0.31 & 0.22 & & & & & & \\
\hline \multicolumn{13}{|l|}{ Residuals: } \\
\hline Tarsus & 0.49 & 0.02 & 0.22 & 0.10 & 0.20 & 0.12 & 0.52 & 0.02 & 0.24 & 0.12 & 0.11 & $<0.01$ \\
\hline Culmen & 0.49 & 0.02 & 0.20 & 0.08 & 0.18 & 0.10 & 0.75 & $<0.01$ & 0.19 & 0.11 & 0.18 & 0.01 \\
\hline Wing & 0.48 & 0.01 & 0.18 & 0.12 & 0.24 & 0.15 & & & & & & \\
\hline Body & 0.48 & 0.02 & 0.14 & 0.11 & 0.28 & 0.19 & & & & & & \\
\hline $\begin{array}{l}\text { Tarsus + Culmen + } \\
\text { Wing + Body }\end{array}$ & 0.52 & 0.05 & 0.16 & 0.13 & 0.24 & 0.12 & & & & & & \\
\hline PC1 & 0.53 & 0.05 & 0.19 & 0.14 & 0.29 & 0.22 & 0.75 & $<0.01$ & 0.25 & 0.12 & 0.14 & $<0.01$ \\
\hline Tarsus + Culmen & & & & & & & 0.42 & 0.03 & 0.14 & 0.10 & 0.10 & $<0.01$ \\
\hline
\end{tabular}

${ }^{\mathrm{a}}$ Abbreviation for model parameters: Mass = body mass, Tarsus = diagonal tarsus, Culmen = culmen length, Wing = wing chord, Body =body length, PC1 = first principal component. 


\section{Predictive equations}

For all species, size adjustments to body mass resulted in greater precision of fat or protein estimates over that of body mass alone, which is in part an inherent function of adding parameters to a regression model. However, the magnitude of the improvements was highly variable. Further, with only two exceptions across all cases (fat of wigeon (0.18) and goldeneye ( 0.44 for males, 0.23 for females)), the absolute improvement in $r^{2}$ was $\leq 0.09$ for both fat and protein. However, predictive equations explained a moderate to high percentage of variation in protein across species, although with the exception of harlequin, the inclusion of morphometrics in predictive models accounted for only $25 \%-59 \%$ of the variation in fat across species. Thus, even with known quantities of fat or protein, the potential improvement to precision is highly variable, but often low and, in general, adjusting for body size explains only a quarter to half of the variation in fat.

\section{Ratio and residual indices}

Many of the indices used in the literature are what we refer to as unverified indices. That is, they are not validated or tested against known values of fat and protein, and are applied under the assumption that adjusting body mass by measures of structural size in an arbitrary manner results in a more precise index of body condition than use of body mass alone. Our results indicated that this assumption is frequently violated.

In contrast to predictive equations, whether an investigator is interested in either absolute or percent tissue values, accounting for structural size in indices often did not improve predictive ability relative to body mass alone. Among indices, body mass estimated absolute protein equally as well or more precisely $\left(\Delta \mathrm{r}^{2}=<0.01-0.77\right)$ than other indices we considered, and thus could be regarded as the best predictor of absolute protein across species. However, indices predicted percent protein poorly and with considerably more variability. Similarly, the ability of indices to predict absolute and percent fat was highly variable, consistent with Sparling et al. (1992), the best model structure in our analyses varied across species and sex. Importantly, whether estimating values of fat or protein, adjusting mass by structural size often actually reduced model fit, in a few cases quite substantially. Further, improvements to $r^{2}$ by using either a ratio or residual index were negligible when compared to just using field body mass. Thus, our results demonstrate that the assumption that size-adjusted body mass indices are more precise than direct measures of body mass is not universally valid.

We provide demonstration of our results through a hypothetical example. We envision a scenario where a sample of lesser scaup were captured, weighed and measured (these could be $\geq 1$ of many morphometrics) prior to banding and release, with the ultimate objective of relating their subsequent reproductive performance to their absolute body condition at the time of capture (i.e., "do birds with more absolute fat lay larger clutches?"). To address this question, we seek to create an index to body condition using data collected. Clearly, there are sufficient data to calculate an index but no means to validate such an index. Thus, we are forced to select a previously published (or verified) index for our species, use one developed for another species, or arbitrarily select an index. Chappell and Titman (1983) showed that a body mass $\times$ body length ${ }^{-1}$ index to spring and fall condition of lesser scaup was an improved measure relative to body mass alone, although by only $2 \%$, thus, we might logically select this previously published index for use in our study. However, according to the results in Table 2, this index was the poorest predictor of fat among indices we tested for lesser scaup and, therefore, fails to provide a useful index relative to using body mass alone $\left(\Delta r^{2}=-0.09\right)$ for this study. The difference between our results and those of Chappell and Titman (1983) can be attributed to the specificity of indices to study populations and season (Miller 1989, Castro and Myers 1990, Sparling et al. 1992), further disputing the assumed universality of size-adjusted indices. Alternatively, selection of an index developed for another species, such as the mallard Anas platyrhynchos (body mass $\times$ wing $^{-1}$ ) (Whyte and Bolen 1984), again fails to provide a useful index relative to body mass $\left(\Delta \mathrm{r}^{2}=-0.07\right)$ from our sample of scaup. Our final option would be to arbitrarily select an index based on the measures that were collected. The residual of a PC1 regression (Sedinger et al. 1997) is arguably the most common index in the literature, yet, again, this is not a useful index relative to body mass $\left(\Delta \mathrm{r}^{2}=-0.02\right)$ for our scaup example. Ideally, we would have selected the residual of body mass against tarsus which would have maximized precision relative to body mass alone $\left(\Delta r^{2}=0.02\right)$. But of course, given the available data, we have no way of knowing any of the above information. Our point in this example was to demonstrate that if an investigator lacks the data necessary to validate sizeadjustments to body mass, the application of unverified indices is dubious and investigators should understand the potential consequences associated with this uncertainty.

\section{Defining condition}

Researchers applying indices must a priori define the term condition. As we have shown, indices can be interpreted in terms of absolute or relative proportions of protein and lipid. However, our results demonstrate that indices of absolute quantities of protein and lipid are confounded. That is, both absolute protein and lipid were positively correlated with index values. Accordingly, interpretations of ecological relationships associated with these indices are similarly confounded. For example, a positive relationship between an index and reproductive investment could be due to absolute quantities of either lipid or protein (or the combination). Conversely, indices to proportions of body mass were poorly related to percent protein and thus are more directly interpretable in terms of percent lipid.

In reality, investigators that are applying indices to a live animal are estimating an unknown ratio of fat and protein reserves rather than simply estimating fat and/or protein. As we demonstrated, indices that best predicted fat or protein often had different forms. Despite the energetic advantages of lipid over protein, optimal body condition for an 
individual undoubtedly represents a balance of protein and lipid reserves. For example, the storage and maintenance of progressively larger lipid reserves may require increases in structural size (i.e., increases in protein); Ankney and MacInnes (1978) found that structurally larger geese could carry larger lipid reserves. The same process likely occurs within most individuals such that increases in lipid reserves require corresponding increases in structural protein. In other words, fitness is maximized by some optimal ratio of lipid and protein reserves, which may vary across taxa, or cross-seasonally within taxa (Blem 1990). However, few researchers have described or attempted to define body condition in terms of optimal allocations of protein and lipid, thus, use of the term 'body condition', and associated indices, refers to a physiological state that is largely undefined.

\section{Conclusions}

Few validated indices have been developed and limitations on their use add to the difficulty of selecting an index (Sparling et al. 1992, Brown 1996). Moreover, our results support other studies' findings that indices are likely species- and sex-specific. Miller (1989) and Sparling et al. (1992) also suggested that indices may vary seasonally and are specific to the sample populations. Thus, in the absence of applicable indices for every species or the ability to validate specific indices, a universal index is needed or at minimum an understanding of the risks that arise with the 'unverified' selection of condition indices. Sparling et al. (1992) suggested that unless condition indices can be verified through repeated application to known values of fat and protein, subjectively selecting indices likely does little to improve precision over using body mass alone and often may inflate estimated variance. Our data corroborate this assessment and, while slight improvements can be made to predictive ability over body mass alone, subjective selection of an index frequently results in a reduction in precision. Thus, we strongly recommend that investigators use body mass alone to estimate condition for use in ecological models, rather than applying unverified indices. Although our inference in this paper is restricted to species of Anatidae, we suggest that use of unverified indices be discontinued for birds in general. Moreover, we encourage researchers to verify all types of non-invasive indices (e.g., fat and protein scores, abdominal profiles). Collection and laboratory analysis of body composition is required to develop and test indices to body condition that are appropriate, with measured precision, for the species, sex, location, and annual cycle stage of interest. Further, we encourage investigators to be explicit when defining body condition for use in ecological studies regardless of the index used.

Acknowledgements - We thank the numerous lab and field technicians that helped collect and process the data used in this manuscript. We also thank G. A. Baldassarre for planting the seeds of uncertainty that ultimately led us to explore these issues. G. A. Baldassarre, D. V. Derksen, T. F. Fondell, A. J. Green and J. S. Sedinger provided critical review of this manuscript. The U.S. Geological Survey - Alaska Science Center and Exxon Valdez Oil
Spill Trustee Council provided funds for the bird collections and subsequent lab analyses.

\section{References}

Alisauskas, R. T. and Ankney, C. D. 1992. The cost of egg laying and its relation to nutrient reserves in waterfowl. - In: B. D. J. Batt, A. D. Afton, M. G. Anderson, C. D. Ankney, D. H. Johnson, J. A. Kadlec, and G. L. Krapu (eds). Ecology and management of breeding waterfowl. Univ. of Minnesota Press, Minneapolis, pp. 30-61.

Ankney, C. D. and Afton, A. D. 1988. Bioenergetics of breeding northern shovelers: diet, nutrient reserves, clutch size, and incubation. - Condor 90: 459-472.

Ankney, C. D. and MacInnes, C. 1978. Nutrient reserves and reproductive performance of female lesser snow geese. - Auk 95: 459-471.

Arnold, T. W., Anderson, M. G., Emery, R. B., Sorenson, M. D. and de Sobrino, C. N. 1995. The effects of late-incubation body mass on reproductive success and survival of canvasbacks and redheads. - Condor 97: 953-962.

Bergan, J. F. and Smith, L. M. 1993. Survival rates of female mallards wintering in the Playa Lakes region. - J. Wildl. Manage. 57: 570-577.

Blem, C. R. 1990. Avian energy storage. - In: D. M. Power (ed.). Curr. Ornithol. Plenum Press, New York, pp. 59-113.

Blums, P., Clark, R. G. and Mednis, A. 2002. Patterns of reproductive effort and success in birds: path analyses of longterm data from European ducks. - J. Anim. Ecol. 71: 280295.

Brown, M. E. 1996. Assessing body condition in birds. - In: V. Nolan Jr. and E. D. Ketterson (eds). Curr. Ornithol. Plenum Press, New York, pp. 67-135.

Bustnes, J. O., Erikstad, K. E. and Bjorn, T. H. 2002. Body condition and brood abandonment in common eiders breeding in the high arctic. - Waterbirds 25: 63-66.

Burnham, K. P. and Anderson, D. R. 2002. Model selection and multimodel inference: a practical information-theoretic approach. Second ed. - Springer-Verlag, New York.

Castro, G. and Myers, J. P. 1990. Validity of predictive equations for total body fat in sanderlings from different nonbreeding areas. - Condor 92: 205-209.

Chappell, W. A. and Titman, R. D. 1983. Estimating reserve lipids in greater scaup (Aythya marila) and lesser scaup ( $A$. affinis). - Can. J. Zool. 61: 35-38.

Conroy, M. J., Costanzo, G. R. and Stotts, D. B. 1989. Winter survival of female American black ducks on the Atlantic Coast. - J. Wildl. Manage. 53: 99-109.

Conway, C. J., Eddleman, W. R. and Simpson, K. L. 1994. Evaluation of lipid indices of the wood thrush. - Condor 96: 783-790.

Dobush, G. R., Ankney, C. D. and Krementz, D. G. 1985. The effect of apparatus, extraction time, and solvent on lipid extractions of snow geese. - Can. J. Zool. 63: 1917-1920.

Dufour, K. W. and Weatherhead, P. J. 1991. A test of the condition-bias hypothesis using brown-headed cowbirds trapped during the breeding season. - Can. J. Zool. 69: 2686-2692.

Dugger, B. D., Reinecke, K. J. and Fredrickson, L. H. 1994. Late winter survival of female mallards in Arkansas. - J. Wildl. Manage. 58: 94-99.

Dzubin, A. and Cooch, E. G. 1992. Measurements of geese: general field methods. - California Waterfowl Association, Sacramento, California.

Eichholz, M. W. and Sedinger, J. S. 2006. Staging, migration, and winter distribution of Canada and cackling geese staging in Interior Alaska. - J. Wildl. Manage. 70: 1308-1315 
Green, A. J. 2001. Mass/length residuals: measures of body condition or generators of spurious results? - Ecology 82: 1473-1483.

Hepp, G. R., Blohm, R. J., Reynolds, R. E., Hines, J. E. and Nichols, J. D. 1986. Physiological condition of autumnbanded mallards and its relationship to hunting vulnerability. - J. Wildl. Manage. 50: 177-183.

Heusner, A. A. 1982. Energy metabolism and size I. Is the 0.75 mass exponent of Kleiber's equation a statistical artifact? - Respir. Physiol. 48: 1-12.

Hohman, W. L. 1993. Body composition of wintering canvasbacks in Louisiana: dominance and survival implications. - Condor 95: 377-387.

Iverson, G. C. and Vohs, P. A., Jr. 1982. Estimating lipid content of sandhill cranes from anatomical measurements. - J. Wildl. Manage. 46: 478-483.

Johnson, D. H., Krapu, G. L., Reinecke, K. J. and Jorde, D. G. 1985. An evaluation of condition indices for birds. - J. Wildl. Manage. 49: 569-575.

Miller, M. R. 1989. Estimating carcass fat and protein in northern pintails during the nonbreeding season. - J. Wildl. Manage. 53: $123-129$.

Miller, S. L., Gregg, M. A., Kuritsubo, A. R., Combs, S. M., Murdock, M. K, Nilsson, J. A., Noon, B. R. and Botzler, R. G. 1988. Morphometric variation in tundra swans: relationships among sex and age classes. - Condor 90: 802-815.

Ormerod, S. J. and Tyler, S. J. 1990. Assessments of body condition in dippers Cinclus cinclus: potential pitfalls in the derivation and use of condition indices based on body proportions. - Ring. \& Migr. 11: 31-41.

Owen, M. and Cook, W. A. 1977. Variations in body weight, wing length and condition of mallard Anas platyrhynchos platyrhynchos and their relationship to environmental changes. - J. Zool. (London) 183: 377-395.

Perfito, N., Schirato, G., Brown, M. and Wingfield, J. C. 2002. Response to acute stress in the harlequin duck (Histrionicus histrionicus) during the breeding season and moult: relation- ships to sex, condition, and life-history stage. - Can. J. Zool. 80: $1334-1343$

Ringelman, J. K. 1988. Examining waterfowl condition: skewed ideas on the normal procedure. - In: M. W. Weller (ed.), Waterfowl in winter. Univ. of Minnesota Press, Minneapolis, pp. 277-285.

Ringelman, J. K. and Szymczak, M. R. 1985. A physiological condition index for wintering mallards. - J. Wildl Manage. 49: 564-568.

Robbins, C. T. 1993. Wildlife feeding and nutrition. Second ed. - Academic Press Inc., San Diego.

SAS Institute 2003. SAS/STAT user's guide, ver. 8.0. v8.0. SAS Inst.

Schulte-Hostedde, A. I., Zinner, B., Millar, J. S. and Hickling, G. J. 2005. Restitution of mass-size residuals: validating body condition indices. - Ecology 86: 155-163.

Sedinger, J. S., Ankney, C. D. and Alisauskas, R. T. 1997. Refined methods for assessment of nutrient reserve use and regulation of clutch size. - Condor 99: 836-840.

Sheeley, D. G. and Smith, L. M. 1989. Tests of diet and condition bias in hunter-killed northern pintails. $-\mathrm{J}$. Wildl. Manage. 53: 765-769.

Sparling, D. W., Barzen, J. A., Lovvorn, J. R. and Serie, J. R. 1992. An evaluation of regression methods to estimate nutritional condition of canvasbacks and other water birds. - U.S. Dept. of the Interior, Fish and Wildlife Service, Biol. Rep. 3, Washington.

van der Meer, J. and Piersma, T. 1994. Physiologically inspired regression models for estimation and predicting nutrient stores and their composition in birds. - Physiol. Zool. 67: 305-329.

Whyte, R. J. and Bolen, E. G. 1984. Variation in winter fat depots and condition indices of mallards. - J. Wildl. Manage. 48: $1370-1373$.

Yerkes, T. 1998. The influence of female age, body mass, and ambient conditions on redhead incubation constancy. - Condor 100: 62-68. 